\title{
Development of nucleic acid based techniques and possibilities of their application to rumen microbial ecology research ${ }^{*}$
}

\author{
E. Pers-Kamczyc ${ }^{1}$, P. Zmora, A. Cieślak and M. Szumacher-Strabel \\ Poznan University of Life Sciences, \\ Department of Animal Nutrition and Feed Management, RUMEN PULS \\ Wotyńska 33, 60-637 Poznań, Poland
}

(Received 24 May 2011; revised version 1 August 2011; accepted 4 August 2011)

\begin{abstract}
Despite many years of research elucidating processes occurring in the rumen, still only around $10 \%$ of the rumen microbe is known. Molecular biology techniques seem to be a good complement of an information obtained by using the classical microbiology and therefore can enhance our knowledge about processes occurring in the rumen. The aim of this paper is to describe and to summarize a widely used techniques of the molecular biology during analysis of microbes in rumen. The main attention have been focused on the three of them which can be employed for quantitative and qualitative analysis of rumen microorganisms: PCR-DGGE, Real-time PCR and Fluorescence in situ hybridization.
\end{abstract}

KEY WORDS: rumen, microorganisms, molecular techniques, Real time PCR, PCR-DGGE, FISH

\section{INTRODUCTION}

Rumen is one of the richest habitat of numerous microorganism species, which comprises of prokaryotes and eukaryotes. Predominant organisms are bacteria, up to $10^{11}$ viable cells per gram that represent about 200 species. Moreover, a variety

\footnotetext{
* Supported in part by the Ministry of Science and Higher Education, Grant No. N N311 476339 Emilia Pers-Kamczyc has been granted by scholarship START 2011 of the Foundation for Polish Science

${ }^{1}$ Corresponding author: e-mail: emiper@jay.up.poznan.pl
} 
of ciliate protozoa $\left(10^{4}-10^{6}\right.$ per gram, 25 genera) and anaerobic fungi (zoospore population densities of $10^{2}-10^{4}$ per gram, 5 genera) also occur widely. The rumen is affected by a combination of dynamic interactions between the host (ruminant animal) and the microorganisms as well as between microorganisms themselves (Krause and Russell, 1996; Stewart et al., 1997). The final composition of the biocenosis of the rumen ecosystem is the effect of various factors, e.g., diet, feed additives, health, age and condition and species of the animal, season, or geographical conditions (Stewart et al., 1997; Graeme et al., 1998; Wright et al., 2007; Cieślak et al., 2009a; Szumacher-Strabel et al., 2009).

Nowadays, the attention of animal nutritionists is focused on the process that occur in the rumen as the effect of different dietary factors in association with the influence of particular dietary component on rumen microflora, e.g., in terms of improving the feed digestibility (Guan et al., 2008) or modulation of rumen metabolism to mitigate greenhouse gasses emission (Cieślak et al., 2009b; Szumacher-Strabel and Cieślak, 2010).

It should be stressed that the research on the influence of type and composition of diet fed on microbial rumen populations is initially carried out under in vitro conditions and later verified in vivo. Several anaerobic media were developed to allow culturing and isolating as well as describing nutritional preferences of rumen bacteria species (Hespell et al., 1997). Unfortunately, by using traditional microbiological methods, only a small percentage (up to 10\%) of all microorganisms inhabiting rumen has been described. Therefore, a combination of the classical microbiology with advanced molecular methods can increase our understanding of processes occurring within the rumen. The advantage of molecular techniques is lack of microorganisms cultivation and analysis of samples taken directly from the rumen (Tajima et al., 2001) or the multicultural in vitro culture (Bekele et al., 2010; Boguhn et al., 2010).

The molecular biology techniques applied are based on the analysis of $16 \mathrm{~S}$ (procaryota; Deng et al., 2008) or $18 \mathrm{~S}$ (eucaryota; Shin et al., 2004) ribosomal DNA sequences. This is mainly due to the numerous sequences deposited in the database. With the exception of studies based on fluorescence in situ hybridization (FISH; Stabnikova et al., 2006), extraction of DNA/RNA from the rumen sample is needed for molecular analysis. Subsequently, DNA is analysed by polymerasechain reaction assay (PCR). The amplicons can be further examinated by denaturing or terminal gradient gel electrophoresis (DGGE, TGGE, adequately; Mao et al., 2008), ribosomal intergenic spacer analysis (Fisher and Triplett, 1999), terminal restriction fragment analysis (T-RFLP; Liu et al., 1997), as well as cloning and sequencing of PCR amplicons and microarray analysis (Tajima et al., 2001; Bekele et al., 2010; Figure 1). 


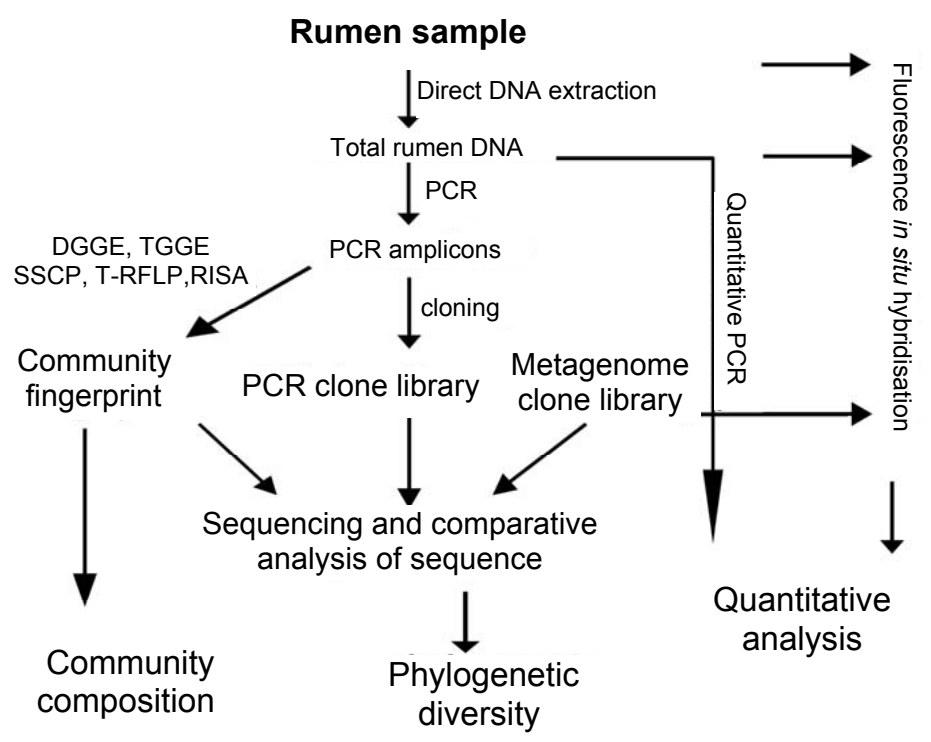

Figure 1. Analysis of microbial communities in the rumen sample by culture-independent molecular methods. PCR - polymerase chain reaction; DGGE - denaturant gradient gel electrophoresis; TGGE - temperature gradient gel electrophoresis; SSCP - single strand conformation polymorphism; T-RFLP - terminal restriction fragment length polymorphism; RISA - ribosomal intergenic spacer analysis

The aim of the present review is to evaluate the existing techniques of molecular biology that can be applied to describe the influence of dietary components on rumen microbial populations.

\section{THE REQUIREMENTS OF MOLECULAR BIOLOGY TECHNIQUES}

Before starting the molecular analysis, the first problem that the researcher encounters, is choosing of the appropriate time of sampling with regards to the time of feeding (before, during or after feeding; Weimer et al., 1999; Denman and McSweeney, 2006). Equally important is the place of rumen from which the samples will be collected (Weimer et al., 1999; Lukas et al., 2010). Depending on the mentioned factors different genus/species of microorganisms will occur, e.g., fibrolytic bacteria exist mostly in solid fraction (Koike and Kobayashi, 2009). Therefore, analysis of most protozoa should be performed on the liquid fraction of rumen fluid (Leng et al., 2011; Singh et al., 2011), while in the case of most bacteria in the fraction of liquid (Tajima et al., 2001), or in mixed samples (Weimer 
et al., 1999). Due to these factors, before collecting a rumen sample, we have to known the habitat niche of the microorganisms we are planning to analyse. Such information will help us to decide from where, when and how the samples should be acquired during experiment (Makkar and McSweeney, 2005).

Obtained samples should be representative and free from bias. This is particularly important in case when quantification is an objective of the study. Rumen fluid sample should be freeze or directly proceed for DNA isolation because of high activities of DNase and RNase. There is also possibility to use frozen bacterial pellet collected after approximately $30 \mathrm{~min}$ of centrifuging with maximum speed (at least $1000 \mathrm{rpm}$ ) at $4^{\circ} \mathrm{C}$ for DNA isolation. Freezing is an effective way of DNA/RNA protection from degradation. It is important to note that repeated thawing of the sample should be avoided prior to the DNA extraction. Extraction of DNA can be conducted directly or indirectly. In a direct method the DNA is extracted from the sample collected directly from the rumen environment. This assay is fast, effective, and what is important, the obtained genomic DNA is more representative. However, it has to be remembered that in the extracted DNA sample some inhibitors may be present. These can inhibit enzymes acting during the amplification reaction or cloning. Therefore, an additional step during direct DNA isolation is needed to remove these inhibitors. This step can be done with the help of commercially available DNA purification kits from companies such as Qiagen or Sigma. The indirect method involves DNA isolation from pure culture microorganisms that have been isolated earlier with the classic microbial methods from rumen sample. This method is time-consuming, laborious and reduces the genetic diversity of environmental DNA. Lower genetic diversity within obtained samples is due to lack of an optimized culture system for culturing of many rumen microorganisms. It should be noted, however, that the DNA obtained by this method does not require purification steps during DNA extraction procedure. On behalf of above, it is not surprising, that direct method of DNA extraction from the sample is more commonly used.

DNA extraction follows cell lysis. Due to huge diversity and number of microorganisms present in the rumen fluid, and particularly the existence of difficult-to-lyse microorganisms, different DNA extraction protocols were developed (Tajima et al., 2001; Yu and Morrison, 2004b; Chaudhary et al., 2011). However, all of them are based on enzyme-chemical or mechanic-chemical methods of cell lysis. In the enzyme-chemical based method, cell lysis is done generally with lysozyme, but proteinase $\mathrm{K}$ can be also used. The most common lysis method is a mechanic-chemical one, involving beat-beating in the presence of the detergent. However, as it was shown, the most efficient is the repeated bead beating plus column $(\mathrm{RBB}+\mathrm{C})$ method described by Yu and Morrison (2004b) in which proteinase $\mathrm{K}$, detergent and beat-beating is used. Using this technique, the 
efficiency of DNA isolation can reach 5-6 times more ng of DNA per one ml than the amount of DNA obtained by the commercial kits. After the extraction step the obtained DNA samples should be aliquoted and stored frozen in $-20^{\circ} \mathrm{C}$.

\section{THE DESCRIPTIONS OF MOLECULAR BIOLOGY TECHNIQUES}

\section{Denaturing temperature gradient gel electrophoresis (DGGE/TGGE)}

Molecular techniques, based on the DNA amplification, have been applied to describe the diversity of bacteria present in the rumen. Such techniques are able to provide unique environmental DNA profile, which represents the genetic diversity of microbial community from each sample. Moreover, they let us to assess the structure of microbial communities in environmental rumen samples without cultivation, and further to determine the community dynamics in response to environmental variations. Obtained profiles can be compared with the 'standard profile' or interesting bands [polymerase chain reaction (PCR) amplicons], can be sequenced, and then compared with known sequences placed in Genome Base (http://www.ncbi.nlm.nih.gov/genome) or Ribosomal Database Project (http:// rdp.cme.msu.edu/). There are several techniques based on PCR assay which can be used to characterize diversity of rumen microbiota, such as RFLP (Restriction Fragment Length Polymorphism; Liu et al., 1997), DGGE (Denaturing Gradient Gel Electrophoresis; Lukas et al., 2010), TGGE (Temperature Gradient Gel Electrophoresis; Nicholson et al., 2007) and SSCP (Single Strand Conformation Polymorphism; Tatsuoka et al., 2007). We will place our attention to the one which is widely used in laboratory work - PCR-DGGE.

PCR-DGGE is the culture-independent fingerprinting technique which is based on the separation of PCR amplicons (up to $500 \mathrm{bp}$ ) of the same size but different sequences (Figure 2). Different sequences are characterized by different denaturation (melting) profile. The theoretical aspects of this separation were firstly described by Fischer and Lerman (1983), however DGGE was introduced into microbial ecology studies by Muyzer et al. (1999). These studies were based on sequences of the ribosomal DNA. So far, many scientists have been using this technique, and in literature there are many papers describing the application of DGGE in research of the structure and evolution of microbial communities from food (Ercolini, 2004), clinical samples (Li et al., 2005), soil (Campbell et al., 2009), waters (Wu et al., 2006), as well as from the rumen (Hernandez-Sanabria et al., 2010). DGGE has been successfully applied to the analysis of human (Chen et al., 2011), pig (Simpson et al., 1999, 2000), cattle (Kocherginskaya et al., 2001; Hernandez-Sanabria et al., 2010), dog (Simpson et al., 2002) and rodent (McCracken et al., 2001) intestinal microbial populations. 


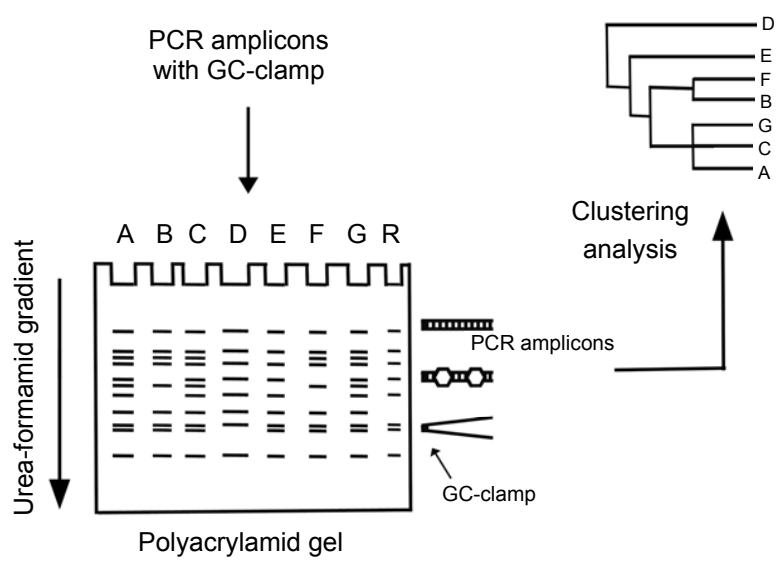

Figure 2. Schematic representation of the principles PCR-DGGE (denaturant gradient gel electrophoresis of amplified DNA). PCR-amplicons are rich in GC base pair at one end of the PCR product. Increasing concentration of denaturant (urea and formamide) along the gel confers the double stranded amplicons into single stranded DNA and therefore decreases their mobility. A GC-clamp attached to the 5' end of one of the PCR primers prevents the amplicon from complete denaturation. Different DNA sequences will result in different origins of melting domains and consequently in different positions in the gel where DNA fragments stop. A, B, C, D, E, F, G - PCR amplicons from different samples, $\mathrm{R}$ - reference

Freitas et al. (2008) have showed that growth of the bacterial population is increased by the presence of soyabean oil, whereas growth retardation occurred when fish oil has been used. The importance of using PCR-DGGE during description of microbial diversity in the rumen has been shown by Lukas et al. (2010). They showed that approximately $80 \%$ of bacterial population attached to the rumen wall can be defined as uncultured. Populations of these bacteria were different from population of bacteria in the rumen content (liquid phase). DGGE technique has been also used to describe effect of disodium fumarate (Mao et al., 2008), type of diet (maize vs hay-fed animals; Kocherginskaya et al., 2001), monensin (Karnati et al., 2009) on bacterial or protozoal communities. Possibility of detection of Oscillospira spp. has been shown by Mackie et al. (2003), as well as description of the ruminal methanogenic community (Yu et al., 2008; Zhou et al., 2010).

Environmental DNA obtained from samples are amplified with the universal primers (Table 1). They can allow us to amplify DNA from almost all microorganisms present in the sample. In PCR-DGGE of bacterial DNA, primers amplified either a single hypervariable (V) region or a combination of two or three V regions in 16S RNA (rrs genes) (Yu and Morrison, 2004a). Those authors 


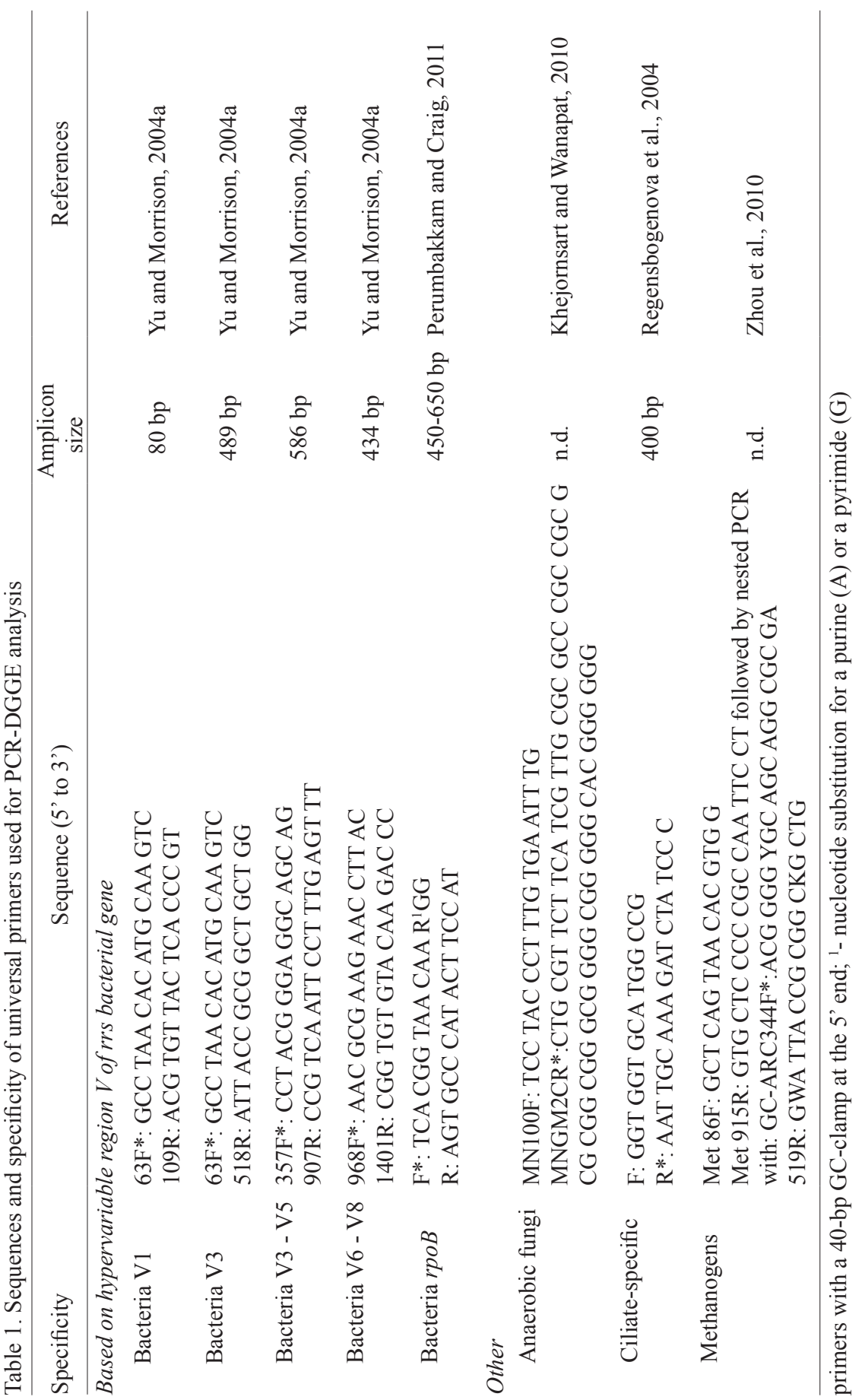


compared several PCR primers which amplified different hypervariable regions of $r$ rs bacterial gene. The analysis showed that the best, representative results are obtained when primers for PCR are located in either the V3 or V1 region of rrs genes. However, when PCR amplicons will be sequenced after analysis, then the V3 to V5 or V6 to V8 region should be targeted. Recently new primer sets were designed and evaluated with bovine and ovine rumen samples (Perumbakkam and Craig, 2011). Primers were based on the sequence of the housekeeping gene - rpo $B$ gene. The authors stated that analysis of $r p o B$ gene sequence (1 copy in bacterial genome) can be a better marker of bacterial diversity than sequence of 16sRNA gene (1-13 copy) and should be used in parallel with another gene marker. PCRDGGE has been also used to describe diversity of ciliate (Regensbogenova et al., 2004) and fungi (Kittelmann and Janssen, 2011; Table 1).

One of primers used for PCR should contain approx. $40 \mathrm{bp}$ of GC on the end; this primer modification is used to stabilize amplicons during electrophoresis. Amplification should be done with the touch-down procedure of DNA amplification (Sadet et al., 2007), what improves primers efficiency.

The obtained PCR amplicons are electrophoretically separated on an acrylamide gel in constant temperature $\left(60^{\circ} \mathrm{C}\right)$, in denaturing conditions which are created by urea and formamide. The gel is prepared by mixing low (without urea and formamide) and high ( $7 \mathrm{M}$ urea and $40 \%$ formamide in water) denaturing solutions together with acrylamide solution, so finally the gel consist linear denaturing gradient. Double-stranded PCR amplicons are exposed to a denaturing factor and with increase of its concentration amplicons become partially melted. Under such conditions, only sequences amplified from genomic DNA of microorganisms are melted. Part of 40-50 GC-clamp remains in double-stranded structure due to higher energy accumulated by GC binding (Sheffield et al., 1989). This form is achieved in the amplicon-specific sequence, known as melting temperature. Partially melted amplicon, creates spatial conformers, which inhibit/prevent the migration of the amplicon in an acrylamide gel. Thus, theoretically amplicons of the same length but with different sequences will behave differently in the environment of denaturing gel, however in practice it is not always like that. Jackson et al. (2000) showed that the same size sequences but with 2 different base pairs had identical migration in DGGE gel.

DGGE electrophoresis can be run in equipment supplied by different companies such as Bio-Rad (USA), INGENY (The Netherlands) and Kucharczyk (Poland). After electrophoresis, separated amplicons are visualized by commonly used ethidium bromide or SYBR Green I staining. However, the most sensitive method is silver staining (Ercolini, 2004). Results of PCR-DGGE electrophoresis are analysed almost always with computer software (e.g., BioNumerics, Quantity One, GELCOMPARII) to describe: the Dice coefficient, dendrogram reflecting 
the relative similarities, diversity indices and the Shannon-Weiner index (Simpson et al., 1999).

PCR-DGGE has been widely used to quantify the microbial biodiversity indices as well as the genetic diversity of rumen microorganisms (Simpson et al., 1999; McCracken et al., 2001) and it is a good way to find new an uncultivated microbes (Simpson et al., 2000). It has to be remembered that the PCR-DGGE cannot be used to determine the microbes that are presenting less than $1 \%$ of the total bacterial community (Zoetendal et al., 2004). Moreover, this technique let us to obtain profile which represents only $90-99 \%$ of the total bacterial population (Zoetendal et al., 1998). One of the features of this technique is the possibility to identify community members present in the rumen sample by sequencing and re-amplifying the bands, or in situ hybridization (McCracken et al., 2001; Temmerman et al., 2003). Moreover, with this procedure direct identification of microbe can be done (presence of a specific band) as well as relative abundance of different species can be described. It also creates a possibility to provide a semi-quantitative estimation of the genetic diversity of microorganisms in the microhabitat (Vaughan et al., 1999).

\section{Quantitative real-time PCR}

Quantitative PCR is a technique enabling the analysis of quantitative microorganism changes in the sample. In contrast to conventional PCR, in which the amplicon detection occurs at the end of each cycle of reactions, in the quantitative PCR product detection occurs only during the phase of exponential growth. At that time, amplified DNA sequence theoretically should be doubled (MacKay, 2007) and detection of amplicons is possible by the use of fluorescent dyes. The cheapest and most widely used dye is SYBR Green (Zhang and Fang, 2006; MacKay, 2007). It binds to double-stranded DNA structure, thus with the increasing number of double-stranded DNA structure, an increase in the level of sample fluorescence occurs. It has to be mentioned, that SYBR Green binds to every double-stranded structure of DNA, also non-specifically amplified. More specify PCR amplification can be done with, e.g., the 5' nuclease (Taqman) assay is used. In this assay, fluorescence reported dye is combined with a quencher dye. Moreover, presence of a probe is needed in this method. The probe targets specific sequence amplified by the primer and contains on one end the reporter and on the other end quencher (Figure 3). If the probe is intact (the reporter and quencher are close to each other) there is no fluorescence. The probe binds to a specific sequence of the denaturated DNA in, localized between forward and reverse primer binding sites. While Taq polymerase moves along the templates the probe is degraded by the 5'-nuclease activity of the polymerase. Therefore, the quencher 
will be separated from the reporter and an increase in the detected fluorescence will be observed. It means that by using this assay only a specific sequence signal will be obtained, and the presence of non-specific products and primer dimers will not influence the results.
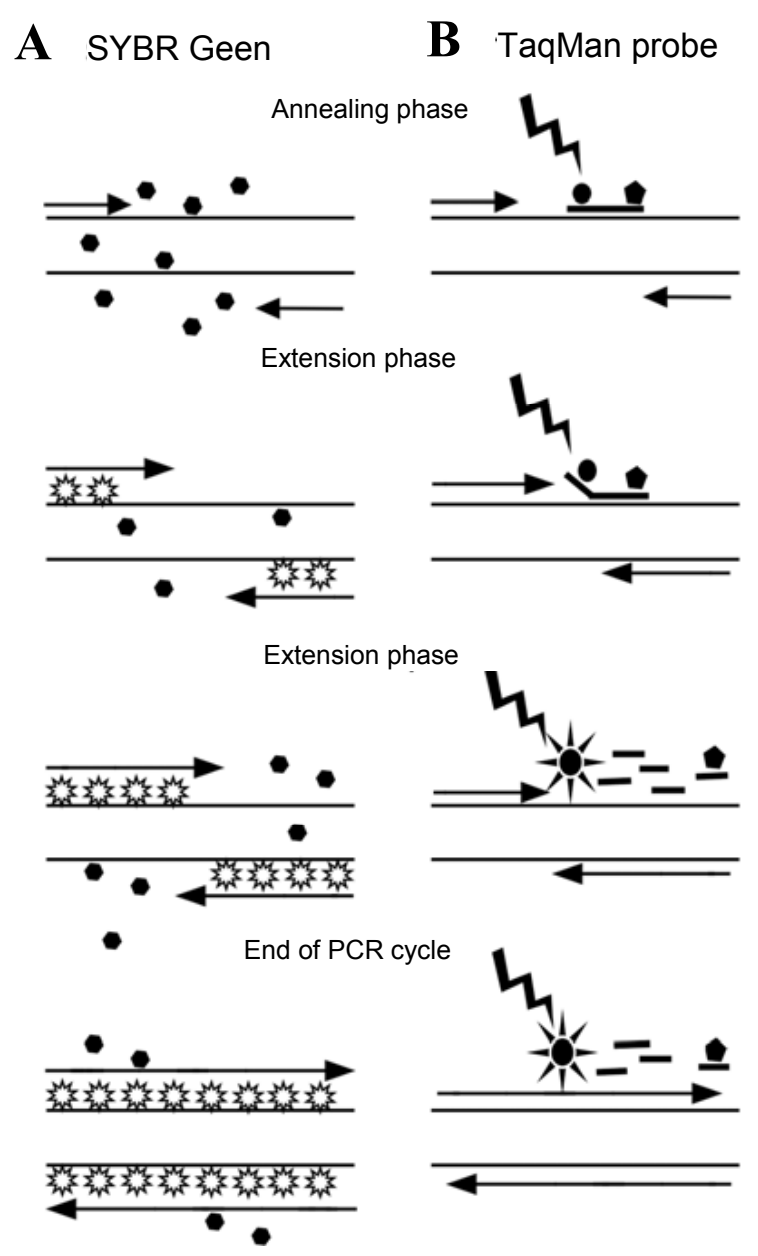

Figure 3. Schematic representation of the principles quantitative real-time PCR with SYBR

Due to the indiscriminate binding of SYBR Green to double stranded DNA, at the end of PCR amplification, specificity of amplicons should be verified. This can be done by monitoring of the dissociation curve. This curve monitors the 
loss of fluorescent signal, during slow growth of temperature from 60 to $90^{\circ} \mathrm{C}$. This increase in temperature causes the release of the SYBR Green due to breaking of double-stranded structure of DNA. A specific signal (single, sharp peak) will appear at sequence specific melting temperature. Non specific products or primer dimmers will appear as broader dissociation peaks.

In real-time PCR the results are interpreted based on the $\mathrm{Ct}$ value (cycle threshold). This value describes number of cycles, in which fluorescence is detected above the background (level of system fluorescence, e.g., plastics, reagents) during an exponential phase. Theoretically, the amount of starting target sample and amount of amplicons within exponential phase of amplification are in quantitative relationship. The change of the $\mathrm{Ct}$ value represents a twofold increase of the amount of starting template. Fluorescence signal obtained during amplification can be transformed to the target gene quantity with several techniques which were grouped into 3 categories: benchmark-based techniques, techniques using regression analysis of fluorescence data and combined techniques (for details see review by Cikos and Koppel, 2009). However two from the benchmark-based techniques category - the absolute standard curve and the comparative method - are frequently used. The standard curve method allows for a direct quantification. The standard curve is constructed by plotting cycles at the Ct against the logarithmic values of known amounts of DNA templates. These curves, as well as amplification efficiency and amount of amplicons can be automatically constructed by software. The reliable standard curve is obtained when the sample and the diluted standard have the same amplification efficiency. Moreover, is should be also remembered, that when rumen sample will be analysed with real-time PCR assay, the standard curve should be performed on serial dilution of DNA extracted from the rumen fluid. First dilution should be $\sim 10 \mathrm{ng} / \mu 1$ of DNA. The amounts of the DNA template are always calculated in number of copies or DNA mass.

Second technique is based on relative quantification of template in the sample. In this method comparison between the target gene and a reference gene ('housekeeping gene', plasmid sequence) is done without the standard curve. The final result expressed the change in the quantity of sample DNA template in comparison to quantity of the reference gene. Ribosomal genes, B-actin or glyceraldehyde-3phosphate dehydrogenase are the most commonly used as the reference genes (Bustin, 2000). It has to be remembered that for proper analysis of the obtained results, primers have to amplified sequence of the reference gene and analysed gene with similar efficiency. The amplification efficiency (E) can be calculated on the base of several formulas (see review by Cikos and Koppel, 2009). If primers used during the relative expression (RE) analysis will not have similar efficiency, mathematical formula introduced by Pfaffl (2001) can be applied: 


$$
R E=\frac{\left(E_{\text {target }}\right)^{\Delta \mathrm{Ct} \text { target (control - sample) }}}{\left(E_{\text {target }}\right)^{\Delta \mathrm{Ct} \text { reference (control - sample) }}}
$$

There is one advantage of relative expression quantification compared to direct quantification. Due to the lack of requirement of the standard curve this assay allows to reduce the number of required reactions.

Before starting the real-time PCR analysis it has to be remembered, that (i) the size of amplification products should be between 50-200 bp; (ii) the concentration of used primers should be as low as possible, to reduce primer dimmer amplification; (iii) the concentration of $\mathrm{Mg}^{2+}$ should be optimal to increase the amplification efficiency and specificity; (iv) the primers should be located in sequence with reduced probability of secondary structure interference; (v) PCR products specificity should be always checked by electrophoresis as well as melting procedure; (vi) PCR efficiency of the assay should be always performed (MacKay, 2007).

The real-time PCR assay has been successfully employed to the rumen microbiology studies (Table 2). Tajima et al. (2001) designed specific primers for 12 different bacteria species. However, it has to be remembered that all articles concerning quantitative real-time PCR analysis demonstrated the importance of primers design, to obtain reliable results from the same quantities of starting template. Real-time PCR assay allowed quantitative analysis of many bacteria as well as fungi and ciliates domain as well as bacteria species connected with many of experimental factors (Table 2). There are limited data showing the fungal quantification in rumen with the PCR techniques (Denman and McSweeney, 2006; Sekhavati et al., 2009; Lwin et al., 2011). Recently Lwin et al. (2011) showed using real-time PCR that the fungal population tended to decrease after feeding in the rumen of sheep.

Quantification of the rumen microorganism can be done also with the competitive PCR method (Sekhavati et al., 2009; Table 3). In this technique a known amount of a DNA fragment (a competitor) is added to the sample. An ideal competitor should be (i) amplified by the same primers as the target DNA, (ii) distinguishable from the target DNA (e.g., different size, different restriction fragment pattern). During PCR reaction both templates (the target DNA and competitor) compete for the same set of primers. Due to this competition, the ratio of the amounts of the two amplified products ( $\mathrm{T}: \mathrm{C}$ ratio) reflects the ratio of the amounts of the target DNA (T) and competitor (C). When the T:C ratio $=1$, the initial amount of the target DNA will correspond to the amount of competitor. In the PCR reaction, a series of diluted competitors is added to a known amount 


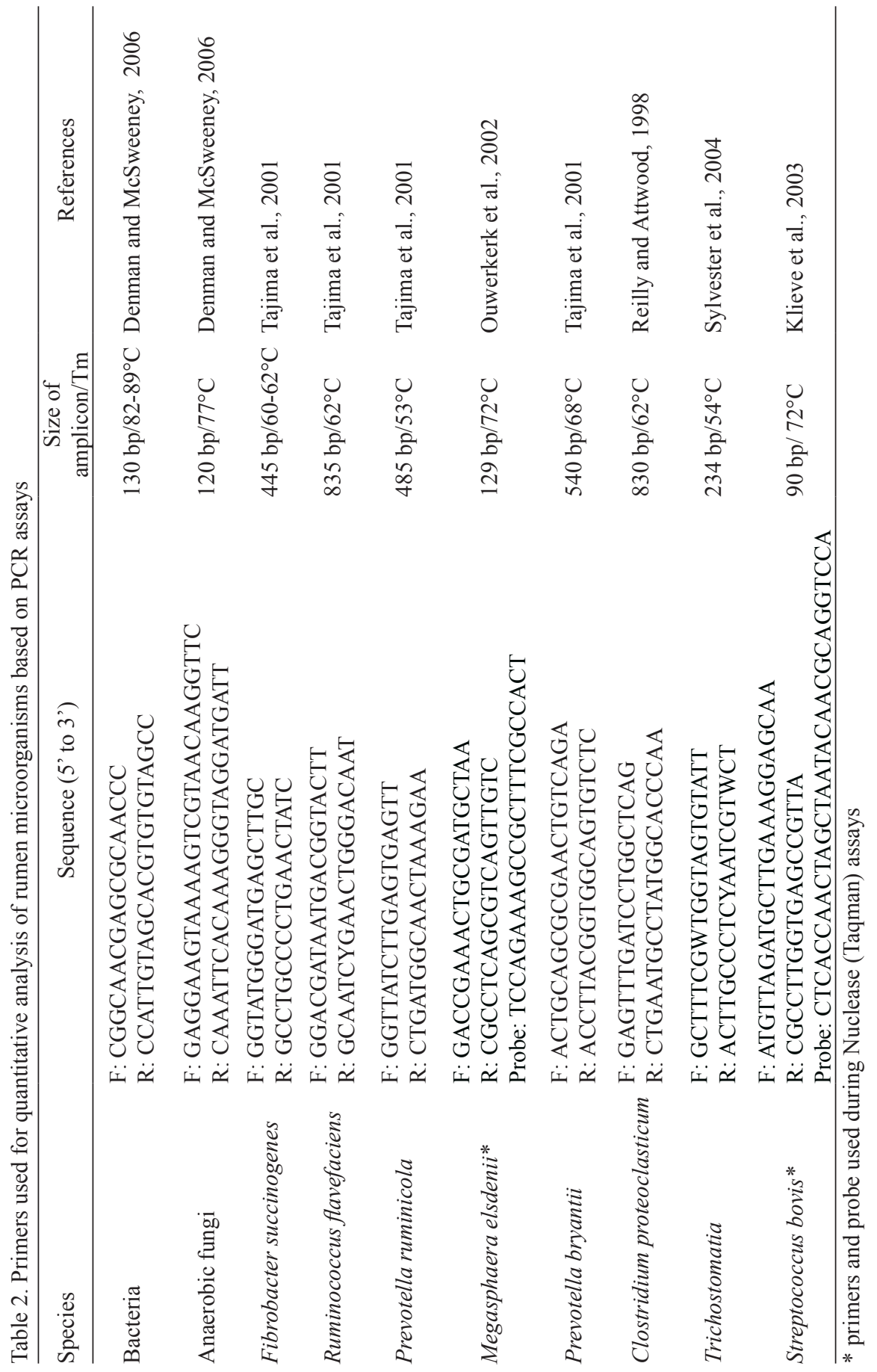




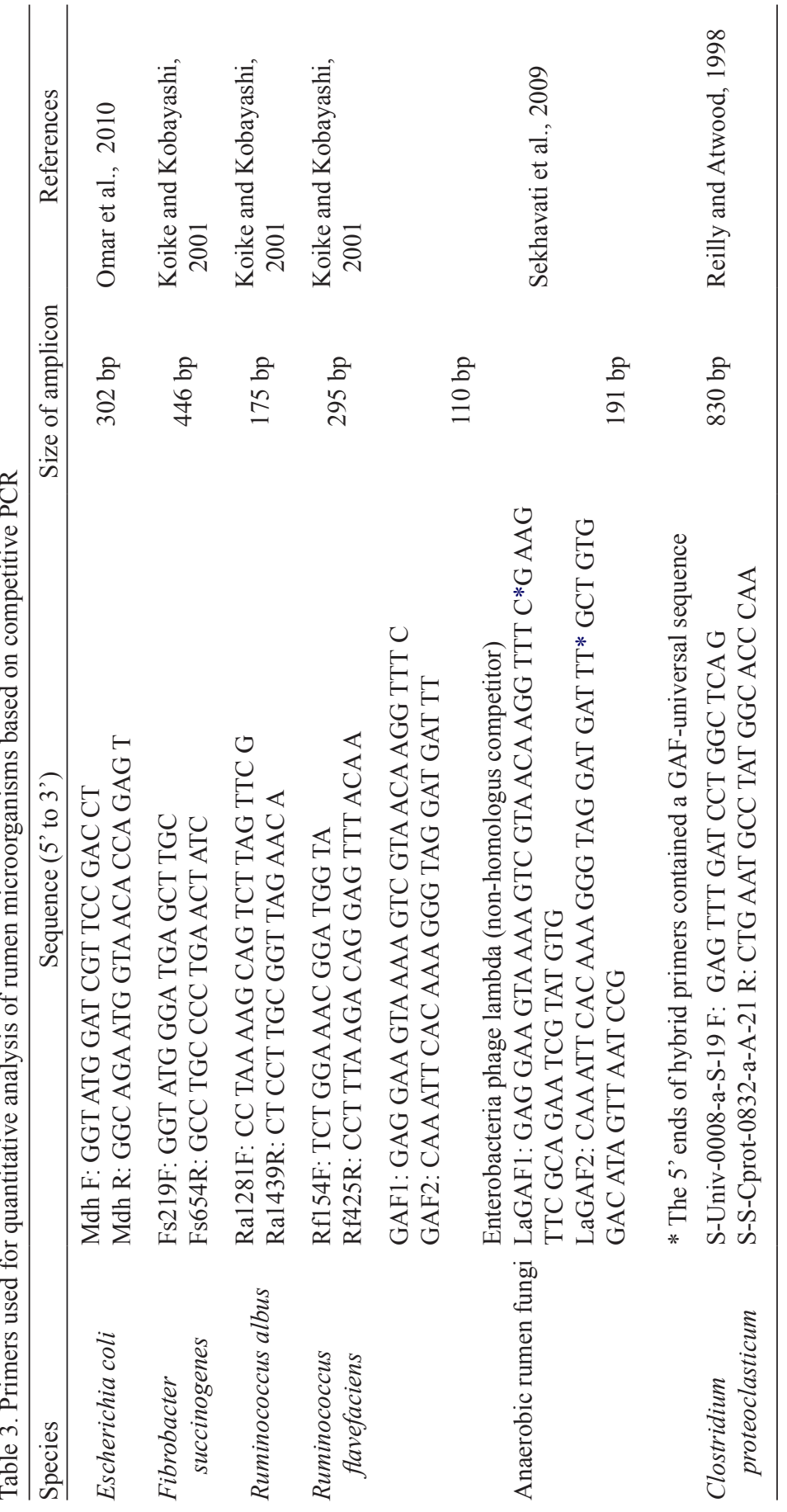


of sample to perform competitive PCR. After completion of the reaction, equal aliquots from each sample are analysed by an agarose gel electrophoresis by visual assessment of band intensities or by digital analysis of the gel image (Omar et al., 2010; Figure 4). It has to be remembered that both methods can be affected by smearing PCR products in the gel, what results in an incorrect/underestimated analysis.

\section{Copy number of competitor}

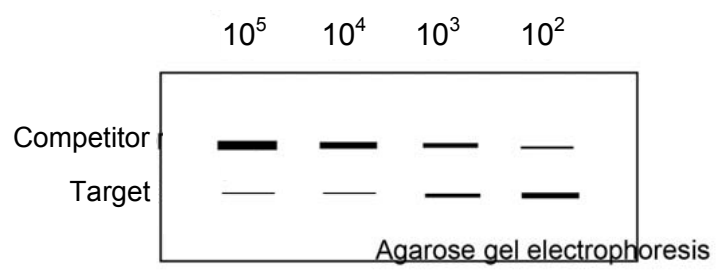

Data analysis

$\begin{array}{rrrrr}\mathrm{T}: \mathrm{C}= & 10 & 3.2 & 1 & 0.32 \\ \log (\mathrm{T}: \mathrm{C})= & 1 & 0.5 & 0 & -0.5\end{array}$

Figure 4. Principle of competitive PCR

\section{Fluorescence in situ hybridization}

Fluorescence in situ hybridization (FISH) is a cytogenetic method, which is mainly used in determination of gene localization in the chromosome (Haferlach and Bacher, 2011; Melo et al., 2011). On the other hand, this technique has been used in the evaluation of microorganisms number without cultivation (Amann et al., 1995; Stabnikova et al., 2006). FISH uses oligonucleotide probes, dyed with the fluorochrome, which are complementary to the specific region of nucleic acid (Wagner et al., 2003; Figure 5). Because in the cell there are many thousands of copies of nucleic acid, this method is very sufficient to visualize the microorganisms by fluorescence microscopy (Stahl and Amann, 1990).

Nowadays, FISH is used very often in molecular microbiology to determine the qualitative and quantitative composition of mixed microbial population (Stabnikova et al., 2006; Amor et al., 2007; Table 4). This technique is very useful, especially in the estimation of the methanogens population in the rumen (Szumacher-Strabel et al., 2011). The Archaea, which live in the digestion system of ruminants, are very difficult to cultivate in vitro (Garcia et al., 2000). Moreover, in the research, where FISH was used, the association of the methanogens with rumen ciliates was showed (Lloyd et al., 1996). 


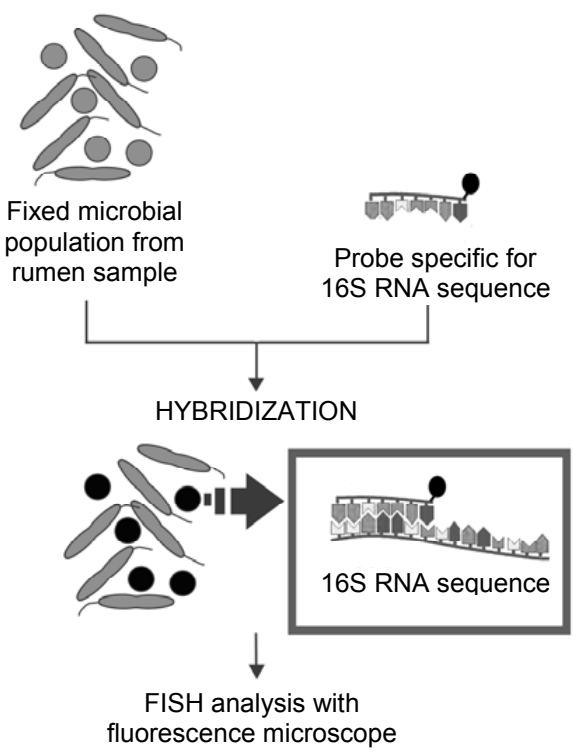

Figure 5. Principles of flourescence in situ hybridization

Table 4. The oligonucleotide probes for quantitative detection of microorganisms

\begin{tabular}{|c|c|c|}
\hline Specificity & Name of probe for sequence ( $5^{\prime}$ to $\left.3^{\prime}\right)$ & References \\
\hline Bacteria & EUB338: GCTGCCTCCCGTAGGAGT & Amann et al., 1990a \\
\hline Archaea & ARC915: GTGCTCCCCCGCCAATTCCT & Amann et al., $1990 \mathrm{~b}$ \\
\hline Archaea & MPB1: CAT GCA CCW CCT CTC AGC & $\begin{array}{l}\text { Jupraputtasri et al., } \\
2005\end{array}$ \\
\hline Methanobacteriales & MG1200: CGGATAATTCGGGGCATGCTG & Raskin et al., 1994 \\
\hline Methanosarcinaceae & FMSC394: ATGCTGGCACTCGGTGTCCC & Narihiro et al., 2009 \\
\hline Methanomicrobium & GMM829: CTCGTAGTTACAGGCACACC & Yanagita et al., 2000 \\
\hline Methanosaeta & GTMS393m: ACCCAGCACTCGAGGTCCCC & $\begin{array}{l}\text { Zheng and Raskin, } \\
2000\end{array}$ \\
\hline Bifidobacterium & Bif228: GATAGGGACGCGACCCCAT & Marteau et al., 2001 \\
\hline $\begin{array}{r}\text { Methanoculleus } \\
\text { thermophilus }\end{array}$ & SMCUT1253: GCCTTTCGGCGTCGATACCC & Narihiro et al., 2009 \\
\hline Lactobacillus plantarum & LbpV3: CCGTCAATACCTGAACAG & Ercolini et al., 2003 \\
\hline Leuconostoc mesenteroides & seucV5: CCTCCTAACACCTAGTGT & Ercolini et al., 2003 \\
\hline Escherichia coli & HEc_L: TTCCTCCCCGCTGAAAGT & $\begin{array}{l}\text { Baudart and Lebaron, } \\
2010\end{array}$ \\
\hline
\end{tabular}


Because FISH does not require the pure culture of microorganisms, it can be used in the determination of microbial mixed population in the rumen. Three main steps should be found in the protocol: (i) cell fixation, (ii) whole-cell hybridization and (iii) analysis in the microscopy (Stahl and Amann, 1990; Figure 5). As a results, some pictures are given, where signals from the fluorescent probes and also signals from the other cells, dyed with non-specific substance (e.g., DAPI) can be found. The comparison of the number of specific and non-specific signals show the diversity of microorganisms in the rumen. To help the analysis after the hybridization, more often the cytometry that shorten the time is used (Tay et al., 2001; Baudart and Lebaron, 2010).

The advantage of using FISH is the possibility of the analysis of biofilm and suspended cell aggregate structures (Stabnikova et al., 2006). With some modifications, it can be also used in quantitative determination of methanogens in attached or suspended microbial aggregates (Stabnikova et al., 2006). Moreover, this technique is quite simple and does not need sophisticated equipment. On the other hand, the procedure is long and laborious and what's more, because of the secondary structure of rRNA and its accessibility and protection in the ribosome, not every oligonucleotide probes can be used in FISH (Amor et al., 2007). Furthermore, on account of high concentration and aggregate structures, it is impossible to measure the quantity of analysed organisms. Only the qualitative detection of, e.g., methanogenic cells is possible (Stabnikova et al., 2006). Also, very important in the fluorescent in hybridization is the cell fixation, especially washing the probes with PBS. It is so important, because in this step, all contaminations are removed. For example in the probes from batch culture, it is enough to wash the probe only 2 time with PBS, but in the samples from in vivo experiments, the washing has to be more often (unpublished data). Moreover, in the analysis under the fluorescent microscopy, very important is the dispersion of the cells. If its cells are too close to them, it is very hard to count them and also the signal from Archaea. Thus, the breakdown of material by ultrasonic waves is recommended (unpublished data)

To sum up, fluorescence in situ hybridization is one of the simplest techniques that can be used in the determination of the microbial population and hence is very often used in laboratory.

\section{CONCLUSIONS}

Advanced molecular techniques can be successfully used during studies of rumen fermentation. In comparison to traditional techniques they let researchers to do their studies faster and more precisely and to examine influence of diet or particular factor in wider aspects on microbiological changes. Despite many 
developed assays still a lot need to be improved to possess better knowledge about processes that occur in the rumen.

\section{REFERENCES}

Amann R., Binder B.J., Olson R.J., Chisholm S., Devereux R., Stahl D.A., 1990b. Combination of 16S rRNA-targeted oligonucleotide probes with flow cytometry for analyzing mixed microbial populations. Appl. Environ. Microbiol. 56, 1919-1925

Amann R., Krumholtz L., Stahl D.A., 1990a. Fluorescent oligonucleotide pro bing of whole cells for determinative, phylogenetic, and environmental studies in microbiology. J. Bacteriol. 172, $762-770$

Amann R.I., Ludwig W., Schleifer H.H., 1995. Phylogenetic identification and in situ detection of individual microbial cells without incubation. Microbiol. Rev. 59,143-169

Amor K.B., Vaughan E.F., de Vos W.M., 2007. Advanced molecular tools for the identification of lactic acid bacteria. J. Nutr. 137, 741-747

Baudart J., Lebaron P., 2010. Rapid detection of E. coli in waters using fluorescent in situ hybridization, direct viable counting and solid phase cytometry. J. Appl. Microbiol. 109, 1253 1264

Bekele A.Z., Koike S., Kobayashi Y., 2010. Genetic diversity and diet specificity of ruminal Prevotella revealed by 16S rRNA gene-based analysis. FEMS Microbiol. Lett. 305, 49-57

Boguhn J., Neumann D., Helm A., Strobel E., Tebbe C.C., Dänicke S., Rodehutscord M., 2010. Effects of concentrate proportion in the diet with or without Fusarium toxin-contaminated triticale on ruminal fermentation and the structural diversity of rumen microbial communities in vitro. Arch. Anim. Nutr. 64, 467-483

Bustin S.A., 2000. Absolute quantification of mRNA using real-time reverse transcription polymerase chain reaction assays. J. Mol. Endocrinol. 25, 169-193

Campbell J.H., Clark J.S., Zak J.C., 2009. PCR-DGGE Comparison of bacterial community structure in fresh and archived soils sampled along a Chihuahuan desert elevational gradient. Microbial Ecol. 57, 261-266

Chaudhary P.P., Sirohi S.K., Kumar S., 2011. Improved extraction of quality DNA from methanogenic archaea present in rumen liquor for PCR application. Asian J. Anim. Sci. 5, 166-174

Chen T., Yuan J., Feng X., Wei H., Hua W., 2011. Effects of enrofloxacin on the human intestinal microbiota in vitro. Int. J. Antimicrobial Agents 37, 567-571

Cieślak A., Váradyová Z., Kišidayová S., Szumacher-Strabel M., 2009a. The effects of linoleic acid on the fermentation parameters, population density, and fatty acid profile of two rumen ciliate cultures, Entodinium caudatum and Diploplastron affine. Acta Protozool. 48, 51-61

Cieślak A., Zmora P., Nowakowska A., Szumacher-Strabel M., 2009b. Limonene affect rumen methanogenesis inhibiting the methanogens populations. Acta Biochim. Pol. 56, Suppl. 2, 5960

Cikos S., Koppel J., 2009. Transformation of real-time PCR fluorescence data to target gene quantity. Anal. Biochem. 384, 1-10

Deng W., Xi D., Mao H., Wanapat M., 2008. The use of molecular techniques based on ribosomal RNA and DNA for rumen microbial ecosystem studies: a review. Mol. Biol. Rep. 35, 265-274

Denman S.E., McSweeney C.S., 2006. Development of a real-time PCR assay for monitoring anaerobic fungal and cellulolytic bacterial populations within the rumen. FEMS Microbiol. Ecol. 58, 572-582 
Ercolini D., 2004. PCR-DGGE fingerprinting: novel strategies for detection of microbes in food. J. Microbiol. Meth. 56, 297-314

Ercolini D., Hill P.J., Dodd C.E.R., 2003. Bacterial community structure and location in stilton cheese. Appl. Environ. Microbiol. 69, 3540-3548

Fischer S.G., Lerman L., 1983. DNA fragments differing by single base-pair substitutions are separated in denaturing gradient gels: correspondence with melting theory. Proc. Nat. Acad. Sci. USA 80, 1579-1583

Fisher M.M., Triplett E.W., 1999. Automated approach for ribosomal intergenic spacer analysis of microbial diversity and its application to freshwater bacterial communities. Appl. Environ. Microbiol. 65, 4630-4636

Freitas K.C., Gabriel J.E., Leite L.C., Dutra de Armas R., Lanna D.P.D., Madeira H.M.F., 2008. Molecular characterization of ruminal bacterial diversity in vitro. Acta Sci. Anim. Sci. 30, 187192

Garcia J.L., Patel B.K.C., Ollivier B., 2000. Taxonomic, phylogenetic, and ecological diversity of methanogenic. Archaea. Anaerobe 6, 205-226

Graeme T., Attwood G.T., Klieve A.V., Ouwerkerk D., Patel B.K.C., 1998. Ammonia-hyperproducing bacteria from New Zealand ruminants. Appl. Environ. Microbiol. 64, 1796-1804

Guan L.L., Nkrumah J.D., Basarab J.A., Moore S.S., 2008. Linkage of microbial ecology to phenotype: correlation of rumen microbial ecology to cattle's feed efficiency. FEMS Microbiol. Lett. 288, 85-91

Haferlach C., Bacher U., 2011. Cytogenetic methods in chronic lymphocytic leukemia. Methods Mol. Biol. 730, 119-130

Hernandez-Sanabria E., Guan L.L., Goonewardene L.A., Li M., Mujibi D.F., Stothard P., Moore S.S., Leon-Quintero M.C., 2010. Correlation of particular bacterial PCR-denaturing gradient gel electrophoresis patterns with bovine ruminal fermentation parameters and feed efficiency traits. Appl. Environ. Microbiol. 76, 6338-6350

Hespell R.B., Akin D.E., Dehority B.A., 1997. Bacteria, fungi and protozoa of the rumen. In: R.I. Mackie, B.A. White, R.E. Isaacson (Editors). Gastrointestinal Microbes and Host Interactions: Gastrointestinal Microbiology. Chapman and Hall, Vol. 2, pp. 85-89

Jackson C.R., Roden E.E., Churchill P.F., 2000. Denaturing gradient gel electrophoresis can fail to separate 16S rDNA fragments with multiple base differences. Mol. Biol. Today 1, 49-51

Jupraputtasri W., Boonapatcharoen N., Cheevadhanarak S., Chaiprasert P., Tanticharoen M., Techkarnjanaruk S., 2005. Use of alternative Archaea-specific probe for methanogen detection. J. Microbiol. Meth. 61, 95-104

Karnati S.K.R., Sylvester J.T., Ribeiro C.V.D.M., Gilligan L.E., Firkins J.L., 2009. Investigating unsaturated fat, monensin, or bromoethanesulfonate in continuous cultures retaining ruminal protozoa. I. Fermentation, biohydrogenation, and microbial protein synthesis. J. Dairy Sci. 99, 3849-3860

Khejornsart P., Wanapat M., 2010. Effect of chemical treatment of rice straw on rumen fermentation characteristic, anaerobic fungal diversity in vitro. J. Anim. Vet. Adv. 9, 3070-3076

Kittelmann S., Janssen P.H., 2011. Characterization of rumen ciliate community composition in domestic sheep, deer, and cattle, feeding on varying diets, by means of PCR-DGGE and clone libraries. FEMS Microbiol. Ecol. 75, 468-481

Klieve A.V., Hennessy D., Ouwerkerk D., Forster R.J., Mackie R.I., Attwood G.T., 2003. Establishing populations of Megasphaera elsdenii YE 34 and Butyrivibrio fibrisolvens YE 44 in the rumen of cattle fed high grain diets. J. Appl. Microbiol. 95, 621-630

Kocherginskaya S., Aminov R.I., White B.A., 2001. Analysis of the rumen bacterial diversity under two different diet conditions using denaturing gradient gel electrophoresis, random sequencing, and statistical ecology approaches. Anaerobe 7, 119-134 
Koike S., Kobayashi Y., 2001. Development and use of competitive PCR assays for the rumen cellulolytic bacteria: Fibrobacter succinogenes, Ruminococcus albus and Ruminococcus flavefaciens. FEMS Microbiol. Lett. 204, 361-366

Koike S., Kobayashi Y., 2009. Fibrolytic rumen bacteria: their ecology and functions. Asian- Austr. J. Anim. Sci. 22, 131-138

Krause D.O., Russell J.B., 1996. How many ruminal bacteria are there? J. Dairy Sci. 79, 14671475

Leng J., Zhong X., Zhu R.J., Yang S.L., Gou X., Mao H.M., 2011. Assessment of protozoa in Yunnan Yellow Cattle rumen based on the 18S rRNA sequences. Mol. Biol. Rep. 38, 577-585

Li Y., Kul C.Y.S., Xu J., Saxena D., Caufield P.W., 2005. Survey of oral microbial diversity using pcr-based denaturing gradient gel electrophoresis. J. Dent. Res. 84, 559-564

Liu W.T., Marsh T.L., Cheng H., Forney L.J., 1997. Characterization of microbial diversity by determining terminal restriction fragment length polymorphisms of genes encoding 16S rRNA. Appl. Environ. Microbiol. 63, 4516-4522

Lloyd D., Williams A.G., Amann R., Hayes A.J., Durrant L., Ralphs J.R., 1996. Intracellular prokaryotes in rumen ciliates protozoa: detection by confocal laser scanning microscopy after in situ hybridization with fluorescent 16S rRNA probes. Eur. J. Protistol. 32, 523-531

Lukas F., Simůnek J., Mrázek J., Kopecný J., 2010. PCR-DGGE analysis of bacterial population attached to the bovine rumen wall. Folia Microbiol. Prague 55, 345-348

Lwin K.O., Hayakawa M., Ban-Tokuda T., Matsui H., 2011. Real-time PCR assays for monitoring anaerobic fungal biomass and population size in the rumen. Curr. Microbiol. 62, 1147-1151

MacKay I.M. (Editor), 2007. Real-time PCR in Microbiology: From Diagnosis to Characterization. Caister Academic Press

Mackie R.I., Aminov R.I., Hu W., Klieve A.V., Ouwerkerk D., Sundset M.A., Kamagata Y., 2003. Ecology of uncultivated Oscillospira species in the rumen of cattle, sheep, and reindeer as assessed by microscopy and molecular approaches. Appl. Environ. Microbiol. 69, 6808-6815

Makkar H.P.S., McSweeney C.S. (Editors), 2005. Methods in Gut Microbial Ecology for Ruminants. IAEA, pp. 3-19

Mao S.Y., Zhang G., Zhu W.Y., 2008. Effect of disodium fumarate on ruminal metabolism and rumen bacterial communities as revealed by denaturing gradient gel electrophoresis analysis of 16S ribosomal DNA. FEMS Microbiol. Ecol. 140, 293-306

Marteau P., Pochart P., Dore J., Bera-Maillet C., Bernalier A., Corthier G., 2001. Comparative study of bacterial groups within the human cecal and fecal microbiota. Appl. Environ. Microbiol. 67, 4939-4942

McCracken V.J., Simpson J.M., Mackie R.I., Gaskins H.R., 2001. Molecular ecological analysis of dietary and antibiotic-induced alterations of the mouse intestinal microbiota. J. Nutr. 131, $1862-1870$

Melo J.B., Backx L., Vermeesch J.R., Santos H.G., Sousa A.C., Kosyakova N., Weise A., von Eggeling F., Liehr T., Carreira I.M., 2011. Chromosome 5 derived small supernumerary marker: towards a genotype/phenotype correlation of proximal chromosome 5 imbalances. J. Appl. Genet. 52, 25-32

Muyzer G., de Waal E.C., Uitterlinden A.G., 1993. Profiling of complex microbial populations by denaturing gradient gel electrophoresis analysis of polymerase chain reaction-amplified genes encoding for 16S rRNA. Appl. Environ. Microbiol. 59, 695-700

Narihiro T., Terada T., Ohashi A., Wu J.H., Liu W.T., Araki N., Kamagata Y., Nakamura K., Sekiguchi Y., 2009. Quantitative detection of culturable methanogenic Archara abundance in anaerobic treatment systems Rusing the sequence-specific rRNA cleavage metod. ISME J. 3, 522-535

Nicholson M.J., Evans P.N., Joblin K.N., 2007. Analysis of methanogen diversity in the rumen using temporal temperature gradient gel electrophoresis: identification of uncultured methanogens. Microbial Ecol. 54, 141-150 
Omar K.B., Barnard T.G., Jagals P., 2010. Development of a competitive PCR assay for the quantification of total Escherichia coli DNA in water. Afr. J. Biotechnol. 9, 564-572

Ouwerkerk D., Klieve A.V., Forster R.J., 2002. Enumeration of Megasphaera elsdenii in rumen contents by real-time Taq nuclease assay. J. Appl. Microbiol. 2, 753-758

Perumbakkam S., Craig A.M., 2011. Design and in vitro evaluation of new rpoB-DGGE primers for ruminants. FEMS Microbiol. Ecol. 76, 156-169

Pfaffl M.W., 2001. A new mathematical model for relative quantification in real-time RT-PCR. Nucl. Acid. Res. 1, 29:e45

Raskin L., Stromley J.M., Rittmann B.E., Stahl D.A., 1994. Group-specific 16S rRNA hybridization probes to describe natural communities of methanogens. Appl. Environ. Microbiol. 60, 12321240

Regensbogenova M., Pristas P., Javorsky P., Moon-van der Staay S.Y., van der Staay G.W., Hackstein J.H., Newbold C.J., McEwan N.R., 2004. Assessment of ciliates in the sheep rumen by DGGE. Lett. Appl. Microbiol. 39, 144-147

Reilly K., Attwood G.T., 1998. Detection of Clostridium proteoclasticum and closely related strains in the rumen by competitive PCR. Appl. Environ. Microbiol. 64, 907-913

Sadet S., Martin C., Meunier B., Morgavi D.P., 2007. PCR-DGGE analysis reveals a distinct diversity in the bacterial population attached to the rumen epithelium. Animal 1, 939-944

Sekhavati M.H., Mesgaran M.D., Nassiri M.R., Mohammadabadi T., Rezaii F., Fani Maleki F., 2009. Development and use of quantitative competitive PCR assays for relative quantifying rumen anaerobic fungal population $\mathrm{s}$ in both in vitro and in vivo systems. Mycol. Res. 113, 1146-1153

Sheffield V.C., Cox D.R., Lerman L.S., Myers R.M., 1989. Attachment of a 40-base-pair G + C-rich sequence (GC-clamp) to genomic DNA fragments by the polymerase chain reaction results in improved detection of single-base changes. Proc. Nat. Acad. Sci. USA 86, 232-236

Shin E.C., Cho K.M., Lim W.J., Hong S.Y., An C.L., Kim Y.K., Choi B.R., An J.M., Kang J.M., Kim H., Yun H.D., 2004. Phylogenetic analysis of protozoa in the rumen contents of cow based on the 18 S rDNA sequences. J. Appl. Microbiol. 97, 378-383

Simpson J.M., McCracken V.J., Gaskins H.R., Mackie R.I., 2000. Denaturing gradient gel electrophoresis analysis of $16 \mathrm{~S}$ ribosomal DNA amplicons to monitor changes in fecal bacterial populations of weaning pigs after introduction of Lactobacillus reuteri strain MM53. Appl. Environ. Microbiol. 66, 4705-4714

Simpson J.M., McCracken V.J., White B.A., Gaskins H.R., Mackie R.I., 1999. Application of denaturant gradient gel electrophoresis for the analysis of the porcine gastrointestinal microbiota. J. Microbiol. Meth. 36, 167-179

Simpson JM, Martineau B, Jones WE, Ballam JM, Mackie RI. 2002. Characterization of fecal bacterial populations in canines: effects of age, breed and dietary fiber. Microbial. Ecol. 44, 186-197

Singh K.M., Tripathi A.K., Pandya P.R., Rank D.N., Kothari R.K., Joshi C.G., 2011. Dasytricha dominance in surti buffalo rumen revealed by $18 \mathrm{~S}$ rRNA sequences and real-time PCR assay. Curr. Microbiol. doi:10.1007/s00284-011-9975-4

Stabnikova O., Liu X.Y., Wang J.Y., Ivanov V., 2006. Quantification of methanogens by fluorescence in situ hybridization with oligonucleotide probe. Appl. Microbiol. Biotechnol. 73, 696-702

Stahl D.A., Amann R.I., 1990. Development and application of nucleic acid probes in bacterial systematics. In: E. Stackebrandt, M. Goodfellow (Editors). Nucleic Acid Techniques in Bacterial Systematics. John Wiley, pp. 205-248

Stewart C.S., Flint H.J., Bryant M.P., 1997. The rumen bacteria. In: P.N. Hobson, C.S. Stewart (Editors). The Rumen Microbial Ecosystem. 2nd Edition. Springer, pp. 49-55 
Sylvester J.T., Karnati S.K.R., Yu Z., Morrison M., Firkins J.L., 2004. Development of an assay to quantify rumen ciliate protozoal biomass in cows using real-time PCR. J. Nutr. 134, 33783384

Szumacher-Strabel M., Cieślak A., 2010. Potential of phytofactors to mitigate rumen ammonia and methane production. J. Anim. Feed Sci. 19, 329-348

Szumacher-Strabel M., Cieślak A., Nowakowska A., 2009. Effect of oils rich in linoleic acid on in vitro rumen fermentation parameters of sheep, goats and dairy cows. J. Anim. Feed Sci. 18, 440-452

Szumacher-Strabel M., Zmora P., Roj E., Stochmal A., Pers-Kamczyc E., Urbańczyk A., Oleszek W., Lechniak D., Cieślak A., 2011. The potential of the wild dog rose (Rosa canina) to mitigate in vitro rumen methane. J. Anim. Feed Sci. 20, 285-299

Tajima K., Aminov R.I., Nagamine T., Matsui H., Nakamura M., Benno Y., 2001. Diet-dependent shifts in the bacterial population of the rumen revealed with real-time PCR. Appl. Environ. Microbiol. 67, 2766-2774

Tatsuoka N., Mohammed N., Mitsumori M., Tajima K., Hara K., Kurihara M., Itabashi H., 2007. Analysis of methanogens in the bovine rumen by polymerase chain reaction single-strand conformation polymorphism. Anim. Sci. J. 78, 512-518

Tay T.L.S., Ivanov V., Kim I.S., Feng L., Tay J.H., 2001. Quantification of ratios of Bacteria and Archaea in methanogenic microbial community by fluorescence in situ hybridization and fluorescence spectrometry. World J. Microbiol. Biotechnol. 17, 583-589

Temmerman R., Masco L., Vanhoutte T., Huys G., Swings J., 2003. Development and validation of a nested-PCR-denaturing gradient gel electrophoresis method for taxonomic characterization of bifidobacterial communities. Appl. Environ. Microbiol. 69, 6380-6385

Vaughan E.E., Heilig H.G.H.J., Zoetendal E.G., Satokari R., Collins J.K., Akkermans A.D.L., de Vos W.M., 1999. Molecular approaches to study probiotic bacteria. Trends Food Sci. Technol. $10,400-404$

Wagner M., Horn M., Daims H., 2003. Fluorescence in situ hybridization for the identification and characterization of prokaryotes. Curr. Opin. Microbiol. 6, 302-309

Weimer P.J., Waghorn G.C., Odt C.L., Mertens D.R., 1999. Effect of diet on populations of three species of ruminal cellulolytic bacteria in lactating dairy cows. J. Dairy Sci. 82, 122-134

Wright A.D., Auckland C.H., Lynn D.H., 2007. Molecular diversity of methanogens in feedlot cattle from Ontario and Prince Edward Island, Canada. Appl. Environ. Microbiol. 73, 4206-4210

Wu Q., Zhao X.H., Zhao S.Y., 2006. Application of PCR-DGGE in research of bacterial diversity in drinking water. Biomed. Environ. Sci. 19, 371-374

Yanagita K., Kamagata Y., Kawaharasaki M., Suzuki T., Nakamura Y., Minato H., 2000. Phylogenetic analysis of methanogens in sheep rumen ecosystem and detection of Methanomicrobium mobile by fluorescence in situ hybridization. Biosci. Biotechnol. Biochem. 64, 1737-1742

Yu Z., Garcia-Gonzalez R.,. Schanbacher F.L, Morrison M.. 2008. Evaluation of different hypervariable regions of archaeal 16S rRNA genes in profiling of methanogens by Archaeaspecific PCR and denaturing gradient gel electrophoresis. Appl. Environ. Microbiol. 74, 889893

Yu Z.T., Morrison M., 2004a. Comparisons of different hypervariable regions of rrs genes for use in fingerprinting of microbial communities by PCR-denaturing gradient gel electrophoresis. Appl. Environ. Microbiol. 70, 4800-4806

Yu Z.T., Morrison M., 2004b. Improved extraction of PCR-quality community DNA from digesta and fecal samples. Biotechniques 36, 808-812

Zhang T., Fang H.H., 2006. Applications of real-time polymerase chain reaction for quantification of microorganisms in environmental samples. Appl. Microbiol. Biotechnol. 70, 281-289 
Zheng D., Raskin L., 2000. Quantification of Methanosaeta species in anaerobic bioreactors using genus- and species-specific hybridization probes. Microbial Ecol. 39, 246-262

Zhou M., Hernandez-Sanabria E., Guan le L., 2010. Characterization of variation in rumen methanogenic communities under different dietary and host feed efficiency conditions, as determined by PCR-denaturing gradient gel electrophoresis analysis. Appl. Environ. Microbiol. 76, 3776-3786

Zoetendal E.G., Akkermans A.L., Devos W.M., 1998. Temperature gradient gel electrophoresis analysis of $16 \mathrm{~S}$ rRNA from human fecal samples reveals stable and host-specific communities of active bacteria. Appl. Environ. Microbiol. 64, 3854-3859

Zoetendal E.G., Collier C.T., Koike S., Mackie R.I., Gaskins H.R., 2004. Molecular ecological analysis of the gastrointestinal microbiota: A review. J. Nutr. 134, 465-472 